\title{
Wiener Index of Some Cycle Related Graphs using Matlab
}

\author{
K. Thilakam \\ Seethalakshmi Ramaswami College, \\ Tiruchirappalli - 620 002, Tamil Nadu, India
}

\author{
A. Sumathi \\ Seethalakshmi Ramaswami College, \\ Tiruchirappalli - 620 002, Tamil Nadu, India
}

\begin{abstract}
The Wiener index is one of the oldest molecular-graph-based structure-descriptors. It was first proposed by American Chemist Harold Wiener in 1947 as an aid to determine the boiling point of paraffin. The study of Wiener index is one of the current areas of research in mathematical chemistry. It also gives good correlations between Wiener index (of molecular graphs) and the physico-chemical properties of the underlying organic compounds. That is, the Wiener index of a molecular graph provides a rough measure of the compactness of the underlying molecule. The Wiener index $\mathrm{W}(\mathrm{G})$ of a connected graph $G$ is the sum of the distances between all pairs (ordered) of vertices of G. $W(G)=\frac{1}{2} \sum_{u, v} d(u, v)$ In this paper, we give the program for calculating the Wiener index of Cata-condensed Cyclic graph and two cycles sharing their edges using MATLAB and discuss the coincidence of Wiener indices of Cata-condensed Cyclic graph with its characteristic graph and give the Wiener number for two Cycles sharing maximum and minimum number of edges.
\end{abstract}

\section{Keywords}

Cycle, Distance, Wiener index, MATLAB

\section{INTRODUCTION}

Wiener index is a well-known graph distance invariant introduced by Harold Wiener 50 years ago[11]. It is defined as the half sum of the distances between all pairs of vertices of

$$
\text { G. } \quad W(G)=\frac{1}{2} \sum_{u, v} d(u, v)
$$

Where $d(u, v)$ is the number of edges in a shortest path connecting the vertices $\mathrm{u} \& \mathrm{v}$ in $\mathrm{G}$.

\section{Notation:}

$W(G)=\frac{1}{2} \sum_{u, v} d(u, v)=\sum_{u<v} d(u, v)=\sum_{u_{i}<v_{j}} d\left(u_{i}, v_{j}\right)$

In this paper, we consider finite, nontrivial, simple and undirected graphs. For a graph $\mathrm{G}$, we denote by $\mathrm{V}(\mathrm{G})$ and $\mathrm{E}(\mathrm{G})$, its vertex and edge sets, respectively[3],[4]. A topological index of a graph $\mathrm{G}$ is a numeric quantity related to $\mathrm{G}$. The adjacency matrix of a molecular graph $\mathrm{G}$ with $\mathrm{n}$ vertices is an $\mathrm{n} \times \mathrm{n}$ matrix.

$\mathrm{A}=\left\{\mathrm{a}_{\mathrm{ij}}\right\}$ defined by: $a_{i j}=1$, if vertices $i$ and $j$ are connected by an edge 0 , otherwise.

In the following section, a MATLAB program is presented which is useful for computing the Wiener index some cycle related graphs. We apply this program to compute the adjacency and distance matrices, Wiener indices of the molecular graph.

\section{A MATLAB PROGRAM FOR COMPUTING THE WIENER INDEX OF} A CATA-CONDENSED CYCLIC GRAPH

In [1],[2] Andrey A. Dobrynin has demonstrated about the Wvalues of Cata-condensed Benzenoid graph and hexagonal Chains. In a similar way, Now we define a class of graphs which include molecular graph of Cata-condensed cyclic hydro carbons. These Cyclic graphs are composed exclusively of $\mathrm{m}, \mathrm{n}$ membered Cycles. The Characteristic graph of a given Cyclic graph consists of vertices corresponding to cycle of a graph; two vertices are adjacent iff the corresponding Cycle share an edge. The Cyclic graph is called Cata-condensed if its Characteristic graph is a tree. Here the Characteristic graph of the above graph is isomorphic to star tree. An example of a Cata-condensed Cyclic graph and its Characteristic graph is shown in fig. $1 \mathrm{~b}$. In other words it is called a special case of super subdivision of $\mathrm{C}_{\mathrm{m}}$. Therefore these Cata-condensed Cyclic graph $\mathrm{H}$ of $\mathrm{G}$ is denoted by $\mathrm{SS}\left(\mathrm{C}_{\mathrm{m}}, \mathrm{C}_{\mathrm{n}}\right)$.Subdivision of a graph $\mathrm{S}(\mathrm{G})$ is the graph obtained from $G$ by replacing each of its edge by a path of length two, or equivalently, by inserting an additional vertex into each edge of $G$. Sethuraman. G and Selvaraju .P have introduced an interesting method of construction of super subdivision of graphs [6]. They defined as, a graph $\mathrm{H}$ is said to be arbitrary super subdivision of $\mathrm{G}$ if $\mathrm{H}$ is obtained from $\mathrm{G}$ by replacing every edge $e_{i}$ of $\mathrm{G}$ by a complete bipartite graph $K_{2, m_{i}}$ for some $\mathrm{m}_{\mathrm{i}}, 1, \leq \mathrm{i} \leq \mathrm{t},\left(\mathrm{m}_{\mathrm{i}}\right.$ may vary for each edge $\left.e_{i}\right)$ in such a way that the ends of $e_{i}$ are merged with the two vertices of the 2-vertices part of $K_{2, m_{i}}$, after removing the edge $\mathrm{e}_{\mathrm{i}}$ from G. It is denoted by $\mathbf{S S}(\mathbf{G})$.Recently N. Sridharan and K. Thilakam have determined the Wiener number of super subdivisions of $P_{n}, C_{n}, K_{1, n}$ [7]. K. Thilakam \& A. Sumathi also have determined Wiener Number of Arbitrary Super Subdivisions of Wheel $W_{n}$ and Fan $F_{n}$ [8] and Wiener Index of Arbitrary super subdivision of some cycle related graphs [9]. A graph $\mathrm{H}$ is said to be a super subdivision of a Cycle with Cycle if $\mathrm{H}$ is obtained from the Cycle $\mathrm{C}_{\mathrm{m}}$ by replacing every edge e of $C_{m}$ by $C_{n}$. It is denoted by $\mathbf{S S}\left(\mathbf{C}_{\mathbf{m}} ; \mathbf{C}_{\mathbf{n}}\right)$.It is shown in fig. 1a 


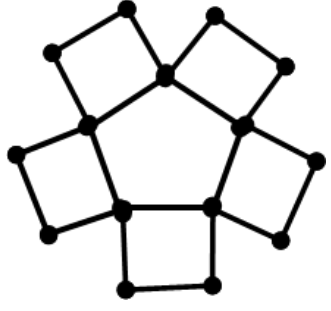

Fig. 1a

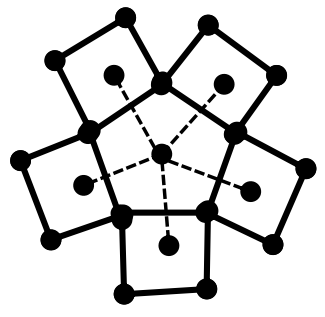

Fig. 1b
$\mathrm{SS}\left(\mathrm{C}_{5} ; C_{4}\right) \quad S S\left(C_{5} ; C_{4}\right)$ with characteristic graph

Here, cycles of a cata-condensed cyclic graph are angularly connected. Each angularly connected cycle is said to correspond to kink in the graph. We now derive new necessary and sufficient conditions that provide the rule of modulo $\mathrm{m}$ and $\mathrm{m} / 2$ for Wiener indices of cata-condensed cyclic graph and its characteristic graph.

\section{Theorem: 2.1}

Let $\mathrm{G}$ be a Cycle graph with $\mathrm{m}$ vertices and $\mathrm{H}$ be the Catacondensed cyclic graph of G. H' be the characteristic graph of $\mathrm{H}$ then

$$
\begin{array}{cc}
W(H) \equiv W\left(H^{\prime}\right) \bmod (m) & \text { if } m \text { be odd } \\
W(H) \equiv W\left(H^{\prime}\right) \bmod (m / 2) & \text { if } m \text { be even }
\end{array}
$$

\section{Proof}

Case1: When m be odd

$$
\text { Since } \mathrm{W}\left(\mathrm{H}^{\prime}\right) \equiv \mathrm{W}\left(\mathrm{K}_{1, \mathrm{~m}}\right) \equiv 0 \bmod (\mathrm{m})
$$

Therefore

$$
\text { and } \mathrm{W}(\mathrm{H}) \equiv 0 \bmod (\mathrm{m})
$$

$$
\mathrm{W}(\mathrm{H}) \equiv \mathrm{W}\left(\mathrm{H}^{\prime}\right) \bmod (\mathrm{m})
$$

Case2: When $m$ be even

Therefore

$$
\begin{gathered}
\text { Since } \mathrm{W}\left(\mathrm{H}^{\prime}\right) \equiv \mathrm{W}\left(\mathrm{K}_{1, \mathrm{~m}}\right) \equiv 0 \bmod (\mathrm{m} / 2) \\
\text { and } \mathrm{W}(\mathrm{H}) \equiv 0 \bmod (\mathrm{m} / 2)
\end{gathered}
$$

$$
\mathrm{W}(\mathrm{H}) \equiv \mathrm{W}\left(\mathrm{H}^{\prime}\right) \bmod (\mathrm{m} / 2)
$$

As a continuation of the work in [10], We compute the Wiener indices of $\operatorname{SS}\left(C_{m} ; C_{n}\right)$ for all $m, n \geq 3$

\section{Programme: 2.1.1}

$\mathrm{m}=$ input('Cycle with vertices $\mathrm{m}=$ ');

$\mathrm{n}=$ input('Cycle with vertices $\mathrm{n}=$ ');

$\mathrm{A}=[\mathrm{]}$;

for $\mathrm{i}=1: \mathrm{m} *(\mathrm{n}-1)$

for $\mathrm{i}=1:(\mathrm{m} *(\mathrm{n}-1))-1$

$\mathrm{A}(\mathrm{i}, \mathrm{i}+1)=1 ; \mathrm{A}(\mathrm{i}+1, \mathrm{i})=1$;

for $\mathrm{i}=\mathrm{m}^{*}(\mathrm{n}-1)$

$\mathrm{A}(1, \mathrm{i})=1 ; \mathrm{A}(\mathrm{i}, 1)=1$;

end

end

end

for $\mathrm{i}=1: \mathrm{n}-1:(m *(n-1))-(2 * \mathrm{n})+4$

$\mathrm{A}(\mathrm{i}, \mathrm{i}+\mathrm{n}-1)=1 ; \mathrm{A}(\mathrm{i}+\mathrm{n}-1, \mathrm{i})=1$;

$\mathrm{A}(1,(\mathrm{~m} *(\mathrm{n}-1))-\mathrm{n}+2)=1 ; \mathrm{A}((\mathrm{m} *(\mathrm{n}-1))-\mathrm{n}+2,1)=1$;

end

A;

$\mathrm{G}=\operatorname{sparse}(\mathrm{A})$;

disp('Distance matrix')

$\mathrm{DM}=$ graphallshortestpaths $(\mathrm{G}$, 'directed',false $)$

$\mathrm{M}=\operatorname{sum}(\operatorname{sum}(\mathrm{DM}))$;
fprintf('Wiener index of sup.sub.of $\mathrm{Cm}$ with $\mathrm{Cn}, \mathrm{W}=\% \mathrm{~d} \backslash \mathrm{n}$ ', $\mathrm{M} / 2$ )

Table 1: Values of $W\left(S S\left(C_{m} ; C_{n}\right)\right)$, for $3 \leq n \leq 10$.

\begin{tabular}{|c|c|c|c|c|c|c|c|c|c|}
\hline \multicolumn{2}{|l|}{$\begin{array}{l}\text { Wiener } \\
\text { Indices }\end{array}$} & \multicolumn{10}{|c|}{$\mathbf{n}$} \\
\cline { 2 - 10 } & $\mathbf{3}$ & $\mathbf{4}$ & $\mathbf{5}$ & $\mathbf{6}$ & $\mathbf{7}$ & $\mathbf{8}$ & $\mathbf{9}$ & $\mathbf{1 0}$ \\
\hline \multirow{3}{*}{$\mathbf{3}$} & $\mathbf{2 1}$ & $\mathbf{6 9}$ & $\mathbf{1 5 3}$ & $\mathbf{2 9 1}$ & $\mathbf{4 8 6}$ & $\mathbf{7 5 9}$ & $\mathbf{1 1 1 0}$ & $\mathbf{1 5 6 3}$ \\
\cline { 2 - 10 } & $\mathbf{4}$ & $\mathbf{4 6}$ & $\mathbf{1 5 2}$ & $\mathbf{3 1 8}$ & $\mathbf{6 0 8}$ & $\mathbf{9 8 6}$ & $\mathbf{1 5 4 4}$ & $\mathbf{2 2 1 8}$ & $\mathbf{3 1 2 8}$ \\
\cline { 2 - 9 } & $\mathbf{5}$ & $\mathbf{8 5}$ & $\mathbf{2 6 5}$ & $\mathbf{5 5 5}$ & $\mathbf{1 0 3 5}$ & $\mathbf{1 6 8 0}$ & $\mathbf{2 5 9 5}$ & $\mathbf{3 7 3 0}$ & $\mathbf{5 2 1 5}$ \\
\cline { 2 - 9 } & $\mathbf{6}$ & $\mathbf{1 4 1}$ & $\mathbf{4 3 5}$ & $\mathbf{8 8 5}$ & $\mathbf{1 6 4 7}$ & $\mathbf{2 6 3 1}$ & $\mathbf{4 0 5 9}$ & $\mathbf{5 7 7 5}$ & $\mathbf{8 0 6 7}$ \\
\cline { 2 - 9 } & $\mathbf{7}$ & $\mathbf{2 1 7}$ & $\mathbf{6 4 4}$ & $\mathbf{1 3 0 9}$ & $\mathbf{2 3 9 4}$ & $\mathbf{3 8 2 2}$ & $\mathbf{5 8 3 8}$ & $\mathbf{8 3 0 2}$ & $\mathbf{1 1 5 2 2}$ \\
\cline { 2 - 9 } & $\mathbf{8}$ & $\mathbf{3 1 6}$ & $\mathbf{9 2 8}$ & $\mathbf{1 8 5 2}$ & $\mathbf{3 3 7 6}$ & $\mathbf{5 3 3 2}$ & $\mathbf{8 1 2 8}$ & $\mathbf{1 1 4 7 6}$ & $\mathbf{1 5 9 0 4}$ \\
\cline { 2 - 9 } & $\mathbf{9}$ & $\mathbf{4 4 1}$ & $\mathbf{1 2 6 0}$ & $\mathbf{2 5 1 1}$ & $\mathbf{4 5 1 8}$ & $\mathbf{7 1 2 8}$ & $\mathbf{1 0 7 8 2}$ & $\mathbf{1 5 2 1 0}$ & $\mathbf{2 0 9 7 0}$ \\
\cline { 2 - 9 } & $\mathbf{1 0}$ & $\mathbf{5 9 5}$ & $\mathbf{1 6 8 5}$ & $\mathbf{3 3 1 5}$ & $\mathbf{5 9 4 5}$ & $\mathbf{9 3 0 5}$ & $\mathbf{1 4 0 4 5}$ & $\mathbf{1 9 7 0 5}$ & $\mathbf{2 7 1 2 5}$ \\
\hline
\end{tabular}

\section{A MATLAB PROGRAM FOR COMPUTING THE WIENER INDEX OF TWO CYCLES SHARING THEIR EDGES}

\section{Definition: 3.1}

Take two copies of cycle with $\mathrm{n}$ vertices then maximum possibility of sharing edges be $n-2$. If it shares $n$ edges, then the resultant graph be cycle with $n$ vertices. If it shares $n-1$ edges, then multiple edges arises. Suppose it shares 1, $2, \ldots \ldots n-2$ edges then finding Wiener indices are very difficult.<smiles></smiles>

NAPHTHALENE $\quad \mathbf{C}_{6}$ sharing 1 edge with $\mathbf{C}_{6}$ Fig.2a

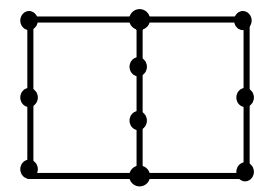

$C_{7}$ sharing 3 edges with $C_{7}$ Fig.2b

Theorem:3.1

Wiener index of two cycles with $n$ vertices sharing t edges is

$$
\begin{aligned}
\mathrm{W}\left(\mathrm{S}\left(\mathrm{C}_{\mathrm{n}} ; \mathrm{t}\right)\right)= & \frac{1}{8}\left[n^{3}+2 n^{2}-n+14\right] \text { when } \mathrm{n} \text { is odd }, \\
& \mathrm{n} \geq 5 \mathrm{t}=\mathrm{n}-2 \\
\mathrm{~W}\left(\mathrm{~S}\left(\mathrm{C}_{\mathrm{n}} ; \mathrm{t}\right)\right)= & \frac{1}{4}\left[3 n^{3}+42 n^{2}+285 n-530\right] \\
& \frac{1}{4}\left[3 n^{3}-6 n^{2}+4\right] \text { when } \mathrm{n} \text { is odd }, \mathrm{t}=1
\end{aligned}
$$


$\mathrm{W}\left(\mathrm{S}\left(\mathrm{C}_{\mathrm{n}} ; \mathrm{t}\right)\right)=\frac{1}{8} n^{3}$ when $\mathrm{n}$ even, $\mathrm{t}=\mathrm{n}$

$$
\frac{1}{8}(n-1) n(n+1) \text { when } \mathrm{n} \text { odd, } \mathrm{t}=\mathrm{n}
$$

The following Programme illustrates Wiener index of two cycles with $\mathrm{n}$ vertices sharing $\mathrm{t}$ edges

\section{Programme:3.2.1}

$\mathrm{n}=$ input('Cycle with vertices $\mathrm{n}=$ '); $\mathrm{t}=$ input(' No. of edges sharing $=$ ');

$\mathrm{A}=[\mathrm{]}$;

if $\mathrm{t}<=\mathrm{n}-3$

for $\mathrm{i}=1: \mathrm{n}$

for $\mathrm{i}=1: \mathrm{n}-1$

$\mathrm{A}(\mathrm{i}, \mathrm{i}+1)=1 ; \mathrm{A}(\mathrm{i}+1, \mathrm{i})=1$;

for $\mathrm{i}=\mathrm{n}$

$\mathrm{A}(1, \mathrm{i})=1 ; \mathrm{A}(\mathrm{i}, 1)=1$;

end

end

end

for $\mathrm{i}=\mathrm{n}+1:(2 * \mathrm{n})-\mathrm{t}-2$

$\mathrm{A}(\mathrm{i}, \mathrm{i}+1)=1 ; \mathrm{A}(\mathrm{i}+1, \mathrm{i})=1$;

$\mathrm{A}(1, \mathrm{n}+1)=1 ; \mathrm{A}(\mathrm{n}+1,1)=1$;

$\mathrm{A}(\mathrm{t}+1,(2 * \mathrm{n})-\mathrm{t}-1)=1 ; \mathrm{A}((2 * \mathrm{n})-\mathrm{t}-1, \mathrm{t}+1)=1$;

end

elseif $\mathrm{t}==\mathrm{n}-2$

for $\mathrm{i}=1: \mathrm{n}$

for $i=1: n-1$

$\mathrm{A}(\mathrm{i}, \mathrm{i}+1)=1 ; \mathrm{A}(\mathrm{i}+1, \mathrm{i})=1$;

for $\mathrm{i}=\mathrm{n}$

$\mathrm{A}(1, \mathrm{i})=1 ; \mathrm{A}(\mathrm{i}, 1)=1$.

end

end

end

$\mathrm{A}(1, \mathrm{n}+1)=1 ; \mathrm{A}(\mathrm{n}+1,1)=1 ;$

$\mathrm{A}(\mathrm{t}+1,(2 * \mathrm{n})-\mathrm{t}-1)=1 ; \mathrm{A}((2 * \mathrm{n})-\mathrm{t}-1, \mathrm{t}+1)=1$;

end

if $\mathrm{t}==\mathrm{n}-1$

disp('Parallel edges arises')

disp('Cannot be determined')

elseif $\mathrm{t}==\mathrm{n}$

disp('Both cycles are identified')

end

disp('Cycle with n vertices')

A;

$\mathrm{G}=\operatorname{sparse}(\mathrm{A})$

disp('Distance matrix')

$\mathrm{DM}=$ graphallshortestpaths $\left(\mathrm{G},{ }^{\prime}\right.$ 'directed',false $)$

$\mathrm{M}=\operatorname{sum}(\operatorname{sum}(\mathrm{DM}))$;

fprintf('Wiener index of G sharing t edges, $W=\% d \backslash n ', M / 2$ )

Table 2: Values of $W\left(S\left(C_{n} ; t\right)\right)$, for $3 \leq n \leq 10$.

\begin{tabular}{|c|c|c|c|c|c|c|c|c|c|}
\hline \multirow{2}{*}{$\begin{array}{c}\text { Wiener } \\
\text { Indices }\end{array}$} & \multicolumn{7}{|c|}{ t } \\
\cline { 2 - 10 } \multicolumn{2}{|c|}{} & 1 & 2 & 3 & 4 & 5 & 6 & 7 & 8 \\
\hline 3 & 7 & - & & & & & & \\
\hline \multirow{2}{*}{$n$} & 4 & 25 & 14 & - & & & & & \\
\hline & 5 & 55 & 36 & 23 & - & & & & \\
\hline
\end{tabular}

\begin{tabular}{|c|c|c|c|c|c|c|c|c|}
\hline 6 & 109 & 78 & 54 & 38 & - & & & \\
\hline 7 & 181 & 138 & 102 & 75 & 56 & - & & \\
\hline 8 & 289 & 230 & 178 & 136 & 105 & 82 & - & \\
\hline 9 & 421 & 346 & 278 & 220 & 174 & 139 & 112 & - \\
\hline 10 & 601 & 506 & 418 & 340 & 275 & 224 & 184 & 152 \\
\hline
\end{tabular}

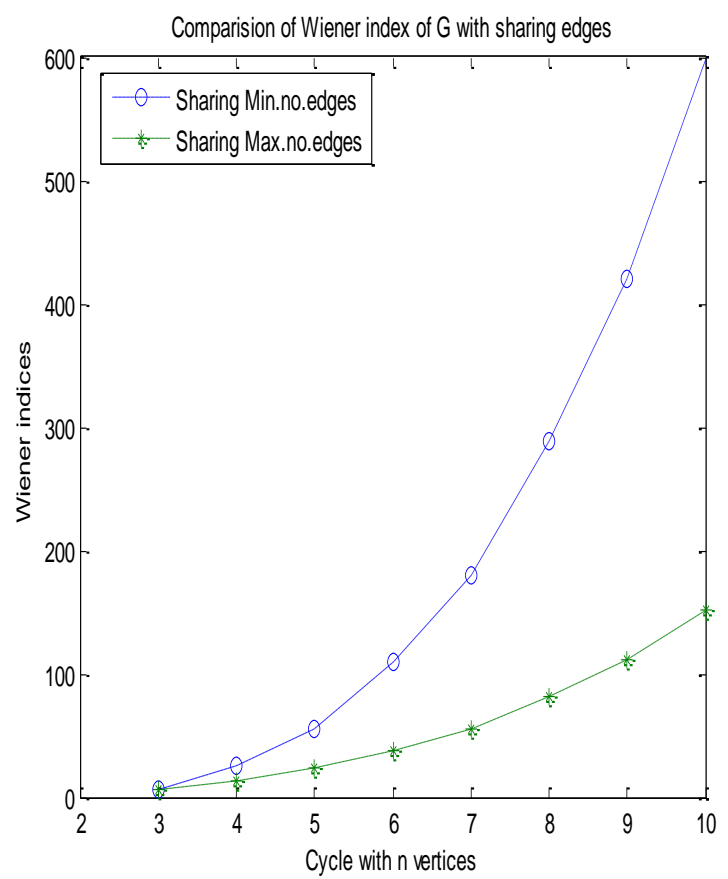

Fig. 3

\section{CONCLUSION}

In this paper, we have given Wiener indices for the special type of super sub division of cycle graph and discussed the congruence relation between $\mathrm{W}(\mathrm{H})$ its characteristic graph. In section 3, we have compared Wiener indices of two equally membered cycles shares maximum and minimum edges. Fig. 3 illustrates that $\mathrm{W}\left(\mathrm{S}\left(\mathrm{C}_{\mathrm{n}} ; \mathrm{t}\right)\right)$ is maximum if it shares minimum number of edges and it is minimum if it shares maximum number of edges. If two cycles shares all the edges together then $\mathrm{W}\left(\mathrm{S}\left(\mathrm{C}_{\mathrm{n}} ; \mathrm{t}\right)\right)=\mathrm{W}\left(\mathrm{C}_{\mathrm{n}}\right)$

\section{REFERENCES}

[1] Andrey A. Dobrynin, Congruence Relations for the Wiener index of Hexagonal Chains, J. chem. Inf. Comput. Sci 1997, 37,1109-1110

[2] Andrey A. Dobrynin, New congruence Relations for Wiener index of Cata-Condensed Benzenoid Graphs, J. chem. Inf. Comput. Sci 1998, 38,405-409.

[3] Balakrishnan R and Ranganathan .K.M, A text Book of Graph Theory,Springer-Verlag, New York,2000

[4] Harary .F, Graph Theory (Addison -Wesley, Reading MA , 1971).J. chem. Inf. Comput. Sci 1997, 37,11091110 .

[5] Mohar .B and Pisanski. T, How to compute the Wiener index of graph, J.Math. Chem., 2(1988),267-277 
[6] Sethuraman .G, Selvaraju.P, Gracefulness of arbitrary super subdivisions of graphs, Indian J. pure appl. Math, 32(7):1059-1064,July 2001.

[7] Sridharan. N and Thilakam. K, Wiener number of super subdivisions of $P_{n}, \quad C_{n}, \quad K_{l, n}, \quad$ Antarctica J.Math.,8(3)(2011),199-211

[8] Thilakam K, Sumathi A, How to Compute the Wiener index of a graph using MATLAB, International Journal of Applied Mathematics\& Statistical Sciences, Vol. 2, Issue 5, Nov 2013, 143-148.
[9] Thilakam. K, Sumathi A, Wiener Index of Arbitrary super subdivision of some cycle related graphs, Jamal Academic Research Journal,vol.6.No.2

[10] Thilakam. K, \& Sumathi A, Wiener Number of Arbitrary Super Subdivisions of Wheel $W_{n}$ and Fan $F_{n}$. Bulletin of Pure and Applied Sciences, Volume 31 E -Math. \& Stat. Issue-2(July-Dec) 2012, 211-216.

[11] Wiener.H , Structural determination of paraffin boiling points, J.Am chem . Soc.69 (1947)17-20.

[12] http://mathworld.wolfram.com/WienerIndex 